\title{
Citation:
}

Gurung, T.R., Stewart, R.A., Beal, C.D., Sharma, A.K. (2016) Investigating the financial implications and viability of diversified water supply systems in an urban water supply zone. Water Resources Management.

DOI: http://dx.doi.org/10.1007/s11269-016-1411-x

\section{Investigating the financial implications and viability of diversified water supply systems in an urban water supply zone}

\section{Authors:}

\section{Thulo Ram Gurung}

Research Fellow, Griffith School of Engineering, Griffith University, Gold Coast Campus, QLD 4222, Australia, E-mail: ram.gurung@griffithuni.edu.au

\section{Rodney A. Stewart}

Professor, Griffith School of Engineering, Griffith University, Gold Coast Campus, QLD 4222, Australia, Email: r.stewart@griffith.edu.au

\section{Cara D. Beal}

Senior Research Fellow, Smart Water Research Centre, Griffith University, Gold Coast Campus, QLD 4222, Australia, E-mail: c.beal@griffith.edu.au

\section{Ashok K. Sharma*}

A/ Professor, Institute of Sustainability and Innovation, Victoria University, PO Box 14428, Melbourne, VIC 8001, Australia, E-mail: ashok.sharma@vu.edu.au

*Corresponding author 


\begin{abstract}
Diversified water supply schemes can reduce both peak demand and overall demand in the urban water supply network. Consequently, they provide benefits to both the water utility and their customers including deferring network augmentations and reducing household water bills, respectively. However, the installation of different water saving scenarios also incurs additional costs which present a financial burden to the householder. This paper investigates the financial viability of installing alternative water supplies and water efficient appliances in a large scale area, taking into account both their benefits and incurred costs. Water demand profiles were developed for the baseline and various water saving scenarios for new dwellings in Queensland, Australia. Hydraulic model runs were conducted to determine system augmentation and pump power requirements for various water saving scenarios across different planning horizons in a water supply study area. The results of the modeling showed deferred augmentations and reduced pumping requirements for the water savings scenarios, compared to the baseline scenario; contributing to monetary savings to the utility. Cost benefits to the householders are from reduced mains water and energy consumption, with incurred costs from installing the water saving systems. A total net cost balance appraisal demonstrated monetary savings for the water efficient and rainwater tank scenarios while the greywater scenario produced negative net costs. The results are discussed along with incentives and potential savings to promote sustainable alternative water use in an urban area.
\end{abstract}

Keywords: Alternative water supplies; water demand modelling; water efficient appliances; water supply network modelling; net cost balance appraisal.

\title{
1 Introduction
}

\subsection{Diversified water supply schemes}

In recent times, attention has been drawn to alternative water solutions and demand management measures to alleviate the unavoidable water shortage problem in the future from population expansion and climate change. It is well documented that alternative water sources and water efficient appliances reduce mains water consumption (e.g. Beal et al., 2012; Domenech and Sauri, 2011; Ghisi and Ferreira, 2007; Umapathi et al., 2013; Zhang et al., 2010), along with other benefits, such as reducing stormwater runoff and pollutant loads (Malinowski, et al., 2015). Recent studies have also reported on their ability to reduce peak water demand (Carragher et al., 2012; Lucas et al., 2010; Umapathi et al., 2013; Willis et al., 2011); an important parameter in water supply planning.

Reductions in volume and peak demand are important as they affect the design of the water supply system by reducing infrastructure size as well as operation and maintenance activities, and contribute directly to financial savings to the water service provider (Cole and Stewart, 2013; Malinowski et al., 2015). For instance, households installed with water efficient appliances resulted in average water supply infrastructure savings of between $10 \%$ and $14 \%$ of original costs (Farmani and Butler, 2014), while various uptakes of rainwater tanks resulted in savings of between $18 \%$ and $53 \%$ from reduced network pipe sizes and operational costs (Lucas et al., 2010). A citywide annual electricity cost savings of between 1\% and 3\% was 
achieved through the implementation of rainwater tanks, and $16 \%$ savings for greywater reuse (Malinowski et al., 2015). Coombes (2007) reported reduced operation and augmentation costs through the extensive installation of rainwater tanks in a regional water supply system, with benefits ranging from AUD\$ 57 to AUD\$ 6,371 per household.

While the cost benefits of using smaller pipes and reduced maintenance and operation activities are instantly noticeable, a lesser acknowledged cost benefit is from the deferrals of future infrastructure upgrades. The deferred expenditure is immediately beneficial to the utility as it is related to the temporal value of money (Gil and Joos, 2006); that is, the value of money reduces over time. Gurung et al. (2016) investigated the deferred expenditure in a water supply zone, where alternative water supplies were installed in new households, over a 50 year planning horizon and presented savings of up to half of the original network capital augmentation costs.

Tam et al. (2010) suggest that the biggest consideration to the householders on installing rainwater tanks lies in the financial costs and benefits, which is also applicable to all water saving measures. Cost studies on the financial viability of installing water saving measures have been done, including determining their cost effectiveness and payback periods (e.g. Farreny et al., 2011; Friedler and Hadari, 2006; Ghisi and Ferreira, 2007; Gurung and Sharma, 2014; Stewart, 2011; Tam et al., 2010). Indeed, while these studies provide some measure of determining the economic effectiveness of diversified water supply schemes, a more complete assessment would be investigating the net cost of each scheme. This is particularly important as it would provide the relevant information for all stakeholders leading to mutually beneficial policy development to encourage their implementation. However, there has been no known research, particularly using a bottom-up modelling approach presented herein, which has investigated the cost benefits of implementing such water saving measures from a total resource cost perspective, that is, the total net benefits from the individual stakeholders (i.e. the utility and the customer) perspective (Stewart, 2011).

\subsection{Study objectives and scope}

While incurred costs and savings from implementing water saving features have been reported at the individual household level, cost savings at the regional scale (both to the water utility and the householders) in a progressively increasing population in a water supply zone have not been investigated. Furthermore, there has been no known previous work which uses high resolution smart water meter data to carry out bottom-up water demand modelling for use in a real-life city water supply network model to explore the life cycle cost implications of a range of alternative strategies. Hence, the current study has the following main objectives:

1. Create average day (AD) demand profiles of baseline and water savings scenarios from empirically based end-use level water demand patterns.

2. Investigate the effects of installing alternative water supplies in a proportion of new infill households on a city's water supply infrastructure requirements from water supply network simulations. 
3. Determine the financial benefits and incurred costs for water consumers implementing alternative water supplies over a citywide scale.

4. Conduct a net benefit cost analysis to understand the financial viability of installing alternative water supplies against the baseline scenario.

The scope of the comparative benefits investigation has been limited to the water supply network within a supply zone (i.e. trunk mains infrastructure, operation and maintenance costs) over a 50- year planning horizon. Other life cycle benefits upstream of the supply zone (i.e. water treatment, reservoir upgrades) have not been considered within the study zone as they are much more difficult to quantify.

\section{Method}

\subsection{Water demand modelling}

\subsubsection{Water demand modelling using smart water meter data}

The study utilises normalised end-use demand patterns, along with design parameters obtained from water utilities, to develop the various water demand profiles which are outlined in further detail in Gurung et al. $(2014 ; 2015 ; 2016)$. As the technique has defined each end-use, the water demand patterns of water saving scenarios can be modelled by modifying the end-use profiles. The indoor normalised water patterns were obtained from high resolution smart water meter sample data from the South East Queensland Residential End Use Study (Beal and Stewart, 2011), while the coarse smart water meter data from Hervey Bay (Cole and Stewart, 2013) provided the normalised outdoor profiles.

\subsubsection{Developing water demand profiles for contemporary water supplies}

Four main water demand profiles were modelled for this study for both single and multi-residential dwellings. Profile A was modelled under a current utility's AD demand of 220 L/p/d (SEQ, 2013) and served as the baseline demand profile for the study (i.e. business as usual), considered to be households constructed in accordance with mandatory water efficiency standards (i.e. 3-star taps and showers, and 4-star clothes washer and toilets) provided in the Queensland Development Code (QDC) Mandatory Part (MP) 4.1 (DHPW, 2013). In this respect, the more stars, the more water efficient the product as per the Water Efficiency and Labelling Standards (WELS) criteria.

Profile B modelled the water demand profiles for households fitted with higher efficiency water appliances than QDC MP 4.1 requirements (i.e. >3-star taps and showers, >4-star clothes washer). 4-star toilets are still modelled for this profile as higher efficiency (>4-star) toilets do not comply with Australian Standards and are not registered under WELS). Measured differences in water efficient and baseline efficient appliances were obtained from Gurung et al. (2015) and applied to each end-use to model their water demand profiles.

Profile C modelled water efficient households (Profile B) fitted with a rainwater tank supplying toilets, cold water laundry, and outdoor use. The rainwater tank is configured with a timer based valve and only allows refilling during periods of low flow (off-peak hours e.g. overnight and afternoon) ensuring that mains water 
peak demand is reduced. The volumetric reliability of the rainwater tank, required in estimating the volume of mains top-up required, was determined through UVQ (Mitchell and Diaper, 2005), an urban water and contaminant balance analysis tool. A roof area of $100 \mathrm{~m}^{2}$, a runoff coefficient of 0.875 and a residential occupancy of 2.73 were used as inputs into the UVQ model. A 20 year rainfall data (1995-2015), obtained from the Bureau of Meteorology (Station ID: 04016), was used as the inflow into the model. Tank demand (outflow) was modelled considering water consumption for toilet, clothes washer (cold) and outdoor use.

Profile D modelled water efficient households (Profile B) fitted to a greywater recycling system connected to toilets, cold water laundry and outdoor use. Biological and filtration treatment were considered to ensure that the greywater is treated effectively for organic and microbial contaminants. Additional demand is provided by mains water during off-peak hours; similar to the rainwater tank.

\subsubsection{Hydraulic modelling and scenarios of study area}

The hydraulic model used in this study is for a water supply zone in South East Queensland (SEQ), Australia as utilised in Gurung et al. (2015). Households in the study area are gravity fed from nine elevated storage tanks, via a network of reticulation $(<200 \mathrm{~mm})$ and trunk mains $(\geq 200 \mathrm{~mm})$ totalling $790 \mathrm{~km}$ in length. Six main pumps convey the water from the reservoir to the storage tanks. EPANET was chosen as the hydraulic solver. In 2011, the network supplied to 213,581 equivalent persons (EP); where EP is the measure of water demand which a single person puts on the local water supply network. The EP demands for the 2016, 2021, 2026, 2031, 2036, 2046, 2056 and 2066 planning horizons were provided by the local water utility. The projected populations were predicted for different residential (multi and single) and non-residential developments, (i.e. industrial, tourist, commercial) for each planning horizon and were based on the latest population and employment forecasts.

Hydraulic model scenarios incorporating the contemporary water supply profiles were created to determine their effects on the water supply infrastructure. The study assumes only new developments having more than 14 dwellings (per household EP at 2.73) are installed with the water saving measures; resulting in their implementation in approximately $60 \%$ of new households at each planning horizon, with the remaining $40 \%$ still modelled under baseline conditions. The modelled scenarios are as follows:

- BASE - Profile A for all new and existing households

- EFF - New households having mix of Profiles A (40\%) and B (60\%)

- RWT - New households having mix of Profiles A (40\%) and C (60\%)

- GWR - New households having mix of Profiles A (40\%) and D (60\%)

\subsubsection{Network augmentation and pumping requirements}

The outcomes of the augmentation scheduling are presented in Gurung et al. (2016). To determine the network augmentation schedules, water supply network modelling was initially done for the 2066 planning horizon. Through a series of hydraulic model runs, the year at when the pipe upgrades were required was determined; that is, when the planning horizon first fails the standards of services outlined in the local 
guidelines (SEQ Code, 2013). For the current study, additional hydraulic model runs were conducted to determine the pumping energy requirements, using a pump efficiency of $70 \%$ based on information from the local utility.

\subsection{Financial analysis}

\subsubsection{Net cost balance computation}

The net present value (NPV) method, expressed by Eq. (1), was used to determine the costs over the analysis period.

$$
N P V=P\left[\frac{(1+j)^{t}}{(1+i)^{t}}\right]
$$

where: $P$ is the cost of component at current prices (2015); $j$ is the component's cost inflation rate; $i$ is the discount rate; and $t$ is the number of years from base year. The financial analysis was conducted using a recommended discount rate of 6\% for water infrastructure projects (DTF, 2003), with the base year as 2015 . A project is seen as viable if the net cost balance (NCB) is positive for the period analysed (Domenech and Sauri, 2011). The NCB over the period can be determined by Eq (2):

$$
N C B=\sum B_{t}-C_{t}
$$

where: $B_{t}$ are the benefits and $C_{t}$ are the incurred costs over the period $t$.

The benefits are the cost savings to the water utility and the householders from installing the water saving scenarios, while the incurred costs relate to their added costs. As the water supply infrastructure is upgraded, water utilities incur additional costs; including capital upgrade costs, and increased operation and maintenance costs. The installation of water saving systems presents cost savings for the water utility as network augmentation works are deferred, and pumping requirements and maintenance works are reduced. For the householders, the cost savings would be from reduced mains hot water and energy use.

The incurred costs are the costs to the householders from installing the water saving system. This includes the capital costs of installing the system, the components' replacement costs at the end of their useful life, and the operation and maintenance costs. Table 1 outlines the costs parameters. 
Table 1 Costs parameters used in financial assessment

\begin{tabular}{|c|c|c|c|c|}
\hline Component & Value & Unit & $\begin{array}{l}\text { Life } \\
\text { (years) }\end{array}$ & Source \\
\hline \multicolumn{5}{|l|}{ Rainwater reuse costs } \\
\hline Tank with accessories & 1,529 & \$/unit & 25 & Gurung et al. (2012) \\
\hline Pump (no auto switch-over) & 500 & \$/unit & 10 & Supplier \\
\hline Timer valve & 105 & \$/unit & 10 & Supplier \\
\hline Plumbing & 888 & \$/unit & 50 & Gurung et al. (2012) \\
\hline Concrete laying (foundation for tank) & 700 & \$/unit & 100 & Gurung et al. (2012) \\
\hline Tank installation & 367 & \$/unit & 25 & Gurung et al. (2012) \\
\hline Electrical installation (pumps) & 200 & \$/unit & 10 & Gurung et al (2012) \\
\hline Sediment check/ cleaning & 162 & $\$ / 3$ years & - & Gurung et al. (2012) \\
\hline Maintenance (additional $\$ 5$ for timer valve) & 25 & \$/annum & - & Stewart (2011) \\
\hline \multicolumn{5}{|l|}{ Greywater reuse costs } \\
\hline Tank with accessories (assumed $80 \%$ of capital costs ${ }^{\mathrm{a}}$ ) & 8,000 & \$/unit & 50 & GHD (2012) \\
\hline Pump and UV (assumed $20 \%$ of capital costs ${ }^{\mathrm{a}}$ ) & 2,000 & \$/unit & 10 & GHD (2012) \\
\hline Timer valve & 105 & \$/unit & 10 & Supplier \\
\hline Plumbing & 888 & \$/unit & 50 & Gurung et al. (2012) \\
\hline $\begin{array}{l}\text { Greywater tank installation (assumed } 80 \% \text { of } \\
\text { installation costs }{ }^{\text {b }} \text { ) }\end{array}$ & 1,600 & \$/unit & 50 & GHD (2012) \\
\hline $\begin{array}{l}\text { Pump and UV installation (assumed } 20 \% \text { of installation } \\
\text { costs }^{\text {b }} \text { ) }\end{array}$ & 400 & \$/unit & 10 & GHD (2012) \\
\hline Maintenance & 270 & \$/annum & 50 & GHD (2012) \\
\hline \multicolumn{5}{|l|}{ Water efficient appliances costs ${ }^{\mathrm{c}}$} \\
\hline Shower & 7 & \$/unit & 20 & Supplier \\
\hline Taps & 7 & \$/unit & 20 & Supplier \\
\hline Washing machine & 98 & \$/unit & 12 & Supplier \\
\hline \multicolumn{5}{|l|}{ Utility charges } \\
\hline Mains water & 3.77 & $\$ / \mathrm{kL}$ & - & CoGC (2015) \\
\hline Household electricity charge & 0.24462 & $\$ / \mathrm{kWh}$ & - & DEWS (2015) \\
\hline Water utility electricity charge & 0.20 & \$/ukWh & - & Per comm CoGC \\
\hline \multicolumn{5}{|l|}{ Energy intensity } \\
\hline Electric hot water system $(\mathrm{HWS})^{\mathrm{d}}$ & 31.6 & $\mathrm{kWh} / \mathrm{kL}$ & - & Vieira et al. (2014) \\
\hline Rainwater pump (trickle top-up system) & 1.59 & $\mathrm{kWh} / \mathrm{kL}$ & - & Umapathi et al. (2013) \\
\hline Greywater pump and UV & 7.2 & $\mathrm{kWh} / \mathrm{kL}$ & - & Diaper (2004) \\
\hline
\end{tabular}

Note: ${ }^{\mathrm{a}}$ Capital costs are estimated as $\$ 10,000$ in GHD (2012). ${ }^{\mathrm{b}}$ Installation costs are estimated as $\$ 2,000$ in GHD (2012). ${ }^{\mathrm{c}}$ The cost of the water efficient appliances is the additional cost of purchasing the efficient appliance. ${ }^{\mathrm{d}}$ For this study, the electric HWS has been considered as it represents the majority of installed HWSs in SEQ

\subsubsection{Inflation rates}

Electricity prices in Queensland are forecasted to increase by 6.2\% and 4\% in 2015/16 and 2016/2017 respectively (AEMC, 2014); an average increase of $5.1 \%$ over the two years. Hence, a $5 \%$ rate was used to inflate future electricity prices. Water prices are forecasted to have an average growth of $2.5 \%$ per annum till 2028 (QCA, 2015), and was used to inflate water charges.

Over the past 10 years in Queensland, there was minimal rise ( 0\%) in the price of household appliances and tools (ABS, 2015a). Hence, a $1 \%$ inflation rate was used to take into account of potential minor increases in 
their prices. For all other components, a base inflation rate of 3.2\% was used, which represents the average rate of increase in construction prices over a similar period (ABS, 2015b).

\section{Results}

\subsection{Water demand modelling}

The baseline profiles for the dwellings in the study were developed using the local water utility's AD demand of $220 \mathrm{~L} / \mathrm{p} / \mathrm{d}$ (SEQ Code, 2013) with $160 \mathrm{~L} / \mathrm{p} / \mathrm{d}$ assigned to indoor use and $60 \mathrm{~L} / \mathrm{p} / \mathrm{d}$ to outdoor use. The results of the peak day demand profiles are presented in Gurung et al. (2016). For this study, the AD demand profile was generated to determine the average pumping energy requirements from the hydraulic model. A demand of $20 \mathrm{~L} / \mathrm{p} / \mathrm{d}$ (SEQ Code, 2013) was added to all the demand profiles to take into account of non-revenue water (e.g. fire flows, system leakage, illegal connections).

The reliability of a $5 \mathrm{~kL}$ rainwater tank was determined to be $69 \%$ based on the configuration described in section 2.1.2, meaning that mains water top-up would be required to meet $31 \%$ of the total tank demand in a given year. Although climate change has the potential to alter the tank's reliability in the future, such unpredictability is difficult to forecast. Hence, the obtained reliability of $69 \%$ is assumed to be standard for all the planning horizons, and was used to model the rainwater reuse demand profile. Hot water demand was estimated as a percentage of total individual appliances consumption; 25\% for clothes washer (EBMUD, 2008), 50\% for shower, taps and bath, and 20\% for dishwasher (Kenway et al., 2008). Table 2 shows the end-uses' $\mathrm{AD}$ and hot water demand for each profile.

Table 2 Estimated AD and hot water demand

\begin{tabular}{lllllll}
\hline & \multicolumn{2}{l}{$\begin{array}{l}\text { Modelled total demand } \\
\text { (L/p/d) }\end{array}$} & & & \multicolumn{2}{l}{$\begin{array}{l}\text { Modelled hot water demand } \\
\text { (L/p/d) }\end{array}$} \\
End uses & Profile A & Profile B & Profile C & Profile D & Profile A & Profiles B, C, D \\
\hline Leak & 7.0 & 7.0 & 7.0 & 7.0 & - & - \\
Toilet & 29.3 & 24.3 & 0.0 & 0.0 & - & - \\
Clothes washer & 35.3 & 21.7 & 5.4 & 5.4 & 8.8 & 5.4 \\
Shower & 56.6 & 40.4 & 40.4 & 40.4 & 28.3 & 20.2 \\
Dishwasher & 2.8 & 2.8 & 2.8 & 2.8 & 0.6 & 0.6 \\
Tap & 26.6 & 23.4 & 23.4 & 23.4 & 13.3 & 11.7 \\
Bathtub & 2.4 & 2.4 & 2.4 & 2.4 & 1.2 & 1.2 \\
Outdoor & 60.00 & 60.0 & 0.0 & 0.0 & - & - \\
Top-up* & N/A & N/A & 31.3 & 22.0 & - & - \\
Non-revenue water** & 20 & 20 & 20 & 20 & - & - \\
\hline Total & 240.0 & 202.0 & 132.7 & 123.4 & 52.2 & 39.1 \\
\hline
\end{tabular}

Note:* Top-up to replenish rainwater and greywater systems. **Non-revenue water represents unaccounted flow within the system.

In comparison to the modelled $\mathrm{AD}$ baseline (Profile A) pattern, Profile B (higher efficiency water appliances) produced lower peaks of $11 \%$ and $21 \%$ for single and multi-residential dwellings, respectively (Fig. 1), while the demand reduced by $16 \%$; from $240 \mathrm{~L} / \mathrm{p} / \mathrm{d}$ to $202 \mathrm{~L} / \mathrm{p} / \mathrm{d}$. In both Profiles C and D, the AD peak demand reduced by $64 \%$ and $56 \%$ for single-residential and multi-residential dwellings, respectively (Fig. 1). These large drops in the peak demand were due to the rainwater and greywater offsetting mains 
demand, while tank replenishment at off-peak hours ensured that the normal peak hours' (i.e. 8 am and $6 \mathrm{pm}$ ) demands are not exacerbated. The mains water demand for Profiles C and D were $133 \mathrm{~L} / \mathrm{p} / \mathrm{d}$ and $123 \mathrm{~L} / \mathrm{p} / \mathrm{d}$, respectively; correspond to significant reductions of $45 \%$ and $49 \%$ in demand.
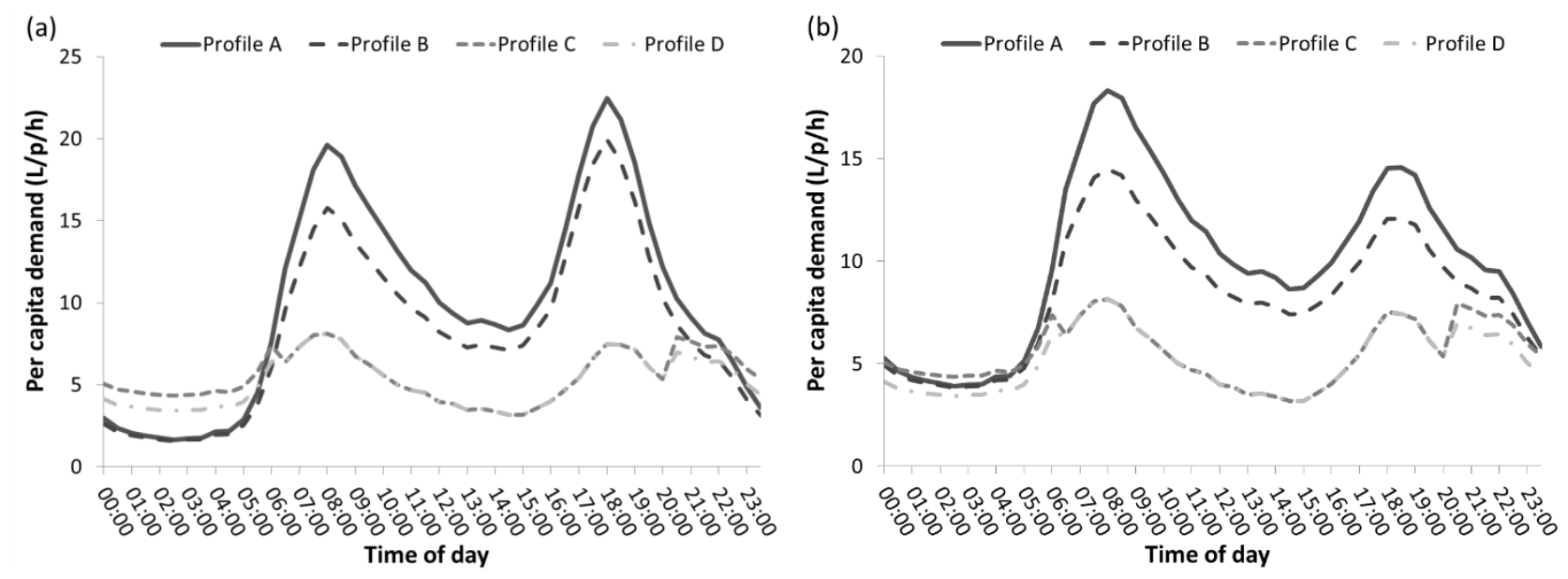

Fig. 1 Modelled AD demand for the various water saving scenarios (a) single-residential households and (b) multi-residential households

\subsection{Water supply network modelling}

A three day extended-period network simulation was undertaken to capture the failure requirements and determine the augmentation requirements. The capital works augmentation scheduling for all modelled scenarios have been determined and discussed comprehensively in Gurung et al. (2016). The study clearly showed that lower peak household water demand from the water saving scenarios resulted in the deferment and size reduction of pipe augmentations, with much of the rescheduling occurring in the longer and larger trunk water mains. The financial results from Gurung et al. (2016) have been included in the current study.

A three day network simulation was carried out to determine the average daily power requirements for all the scenarios, and was then extrapolated over a year to determine the average annual power requirements for each scenario at each planning horizon. The BASE scenario pumping energy requirements rose steadily at each planning horizon from $744 \mathrm{MWh}$ in 2016 to 1,411 MWh by 2066. Energy requirements for the EFF scenario rose from $741 \mathrm{MWh}$ to 1,380 $\mathrm{MWh}$, representing an average decrease of less than $3 \%$ for all planning horizons. Pumping requirements from 2016 to 2066 were similar for the RWT and GWR scenarios; $739 \mathrm{MWh}$ to $1,325 \mathrm{MWh}$ and $739 \mathrm{MWh}$ to $1,309 \mathrm{MWh}$, respectively. The energy reductions for the RWT and GWR scenarios for all planning horizons were less than $7 \%$ and less than $8 \%$, respectively. These energy reductions followed a similar trend to reduced modelled water demand for each scenario. 


\subsection{Financial analysis for the water supply study area}

\subsubsection{Utility cost perspective}

\section{Financial benefits}

The outcomes of the NPV analysis for the infrastructure upgrades and the associated savings for each scenario are shown in Fig. 2. The presented NPV are for the additional population, rather than for the total population of the study area. The maintenance cost was taken to be $0.65 \%$ of the capital costs of all water mains as provided in local guidance (SEQ Code, 2013).

The BASE scenario NPV was $\$ 18.5$ million, with the NPV decreasing progressively for each water saving scenario. The water saving scenario having the lowest peak demand and highest water saving, GWR, provides the lowest infrastructure NPV of $\$ 10$ million. This is followed by the RWT scenario with an NPV of $\$ 10.2$ million and the EFF scenario with $\$ 16.4$ million. The reduced NPV represents respective savings of $46 \%, 44.9 \%$ and $11.3 \%$ of the baseline NPV. Although savings in pumping energy costs were noted, it made up only $5 \%$ to $7 \%$ of total infrastructure savings. Instead, the majority of the savings were from the capital costs upgrades, representing between $76 \%$ and $83 \%$ of total infrastructure savings, with the rest from reduced maintenance requirements ( $12 \%$ to $17 \%$ ).
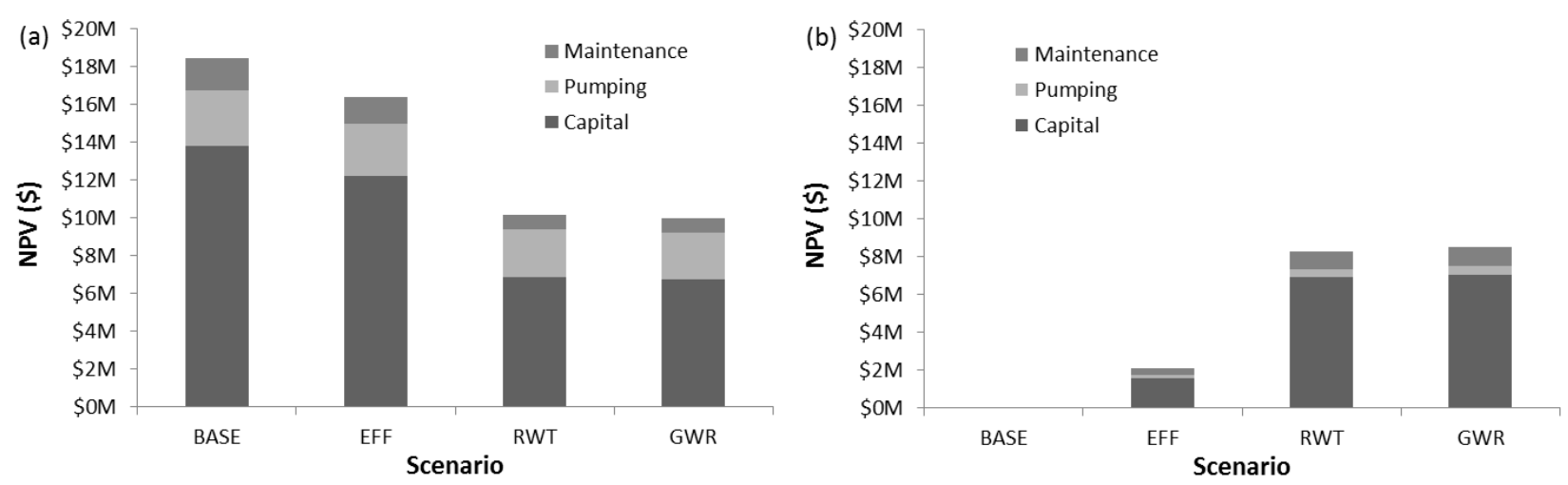

Fig. 2 Breakdown of water supply infrastructure costs (a) total NPV costs (b) total NPV savings

\subsubsection{Householder cost perspective}

\section{Financial benefits}

The NPV and associated costs savings of customers' water and electric HWS energy consumption are shown in Fig. 3. The GWR scenario, which delivers the highest water savings, has the lowest total NPV of \$242.9 million; representing a saving of 39\% of the original baseline NPV of \$398.4 million. The RWT (\$251.3 million) and EFF (\$314.1 million) scenarios produced overall NPV savings of $36.9 \%$ and $21.2 \%$, respectively. The NPV of energy costs savings ( $\$ 49.9$ million) is identical for all the water saving scenarios as their modelled indoor hot water volumes are the same. Energy savings from reduced hot water use represents between $32 \%$ and $59 \%$ of total savings. 

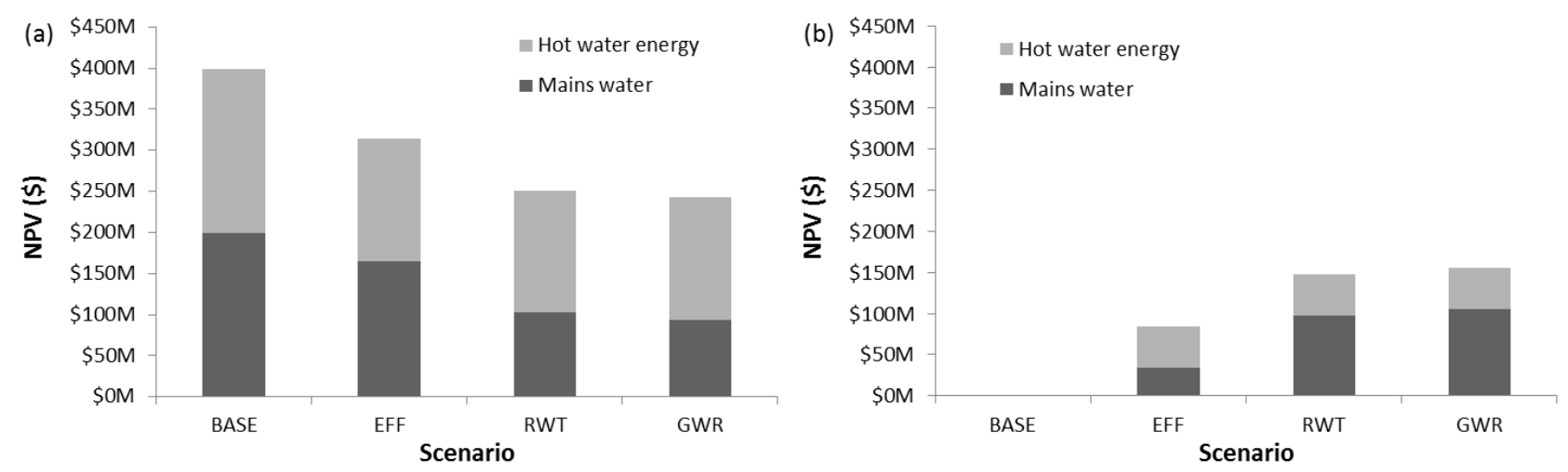

Fig. 3 Breakdown of NPV costs for water consumers (a) total NPV costs and (b) costs savings

\section{Incurred costs}

The incurred costs (i.e. the capital, operation and maintenance costs) for the installation and operation of the water saving features are borne by the householders. The GWR scenario produced the highest NPV of \$385.9 million due to the high installation and running costs. The RWT scenario had a lower NPV of \$126.1 million while the EFF scenario produced the lowest NPV of \$2.1 million.

\subsubsection{Total resource cost perspective for water saving scenarios}

Total value of savings

Through the installation of the water saving measures, the greatest benefits are experienced by the water customers, with respect to total costs savings, from reduced water and energy bills (Fig. 4). Although the water utility also reaps the financial benefits, their proportion of total savings is less than $5.4 \%$ for the water saving scenarios.
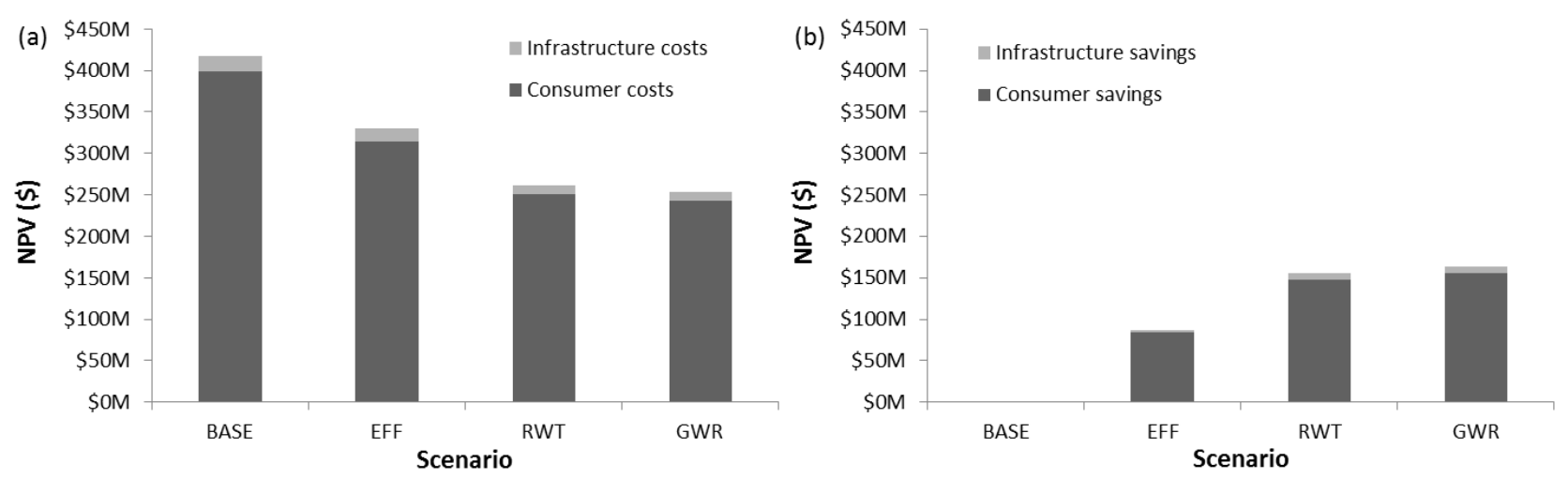

Fig. 4 Breakdown of (a) total NPV costs and (b) total costs savings

\section{Net cost balance}

The NCB computation for the study shows that the GWR scenario is not a financially feasible option as the NPV is negative at $\$ 221.8$ million (Fig. 5). On the other hand, the EFF scenario has the highest NPV of $\$ 84.4$ million, while RWT also produced a positive NPV of \$29.3 million (Fig. 5). The householders' benefits were the main contributors in offsetting the costs of installing the water saving features. Although the GWR scenario incurs considerable costs over the analysis period, householders' savings still managed to 
reduce these costs by $40 \%$ even though the NCB for the GWR scenario is negative. Conversely, a positive $\mathrm{NCB}$ was achieved in both the EFF and RWT scenarios, as householder savings were significantly more than the installation costs.

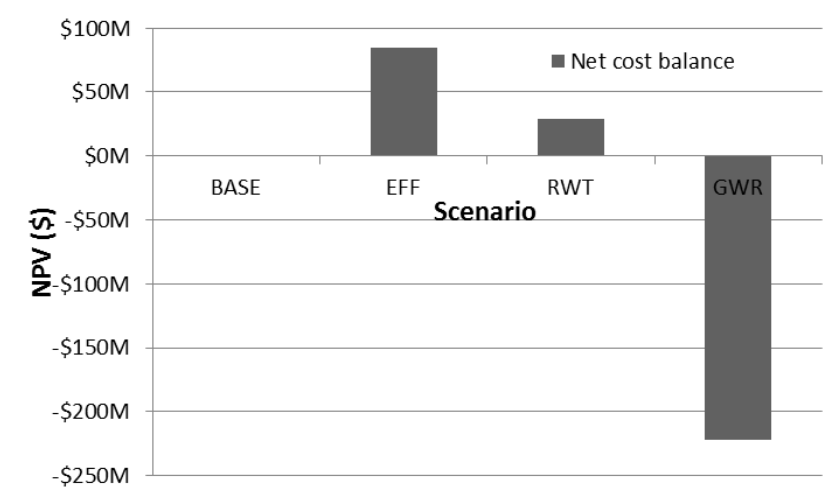

Fig. 5 Net cost balance for each of the water saving scenarios

\section{Discussion}

\subsection{Cost perspectives}

\subsubsection{Utility cost perspective}

The installation of household water saving measures directly reduced the capital costs in the water supply network as smaller sized mains were used and upgrades were eliminated. Further savings were achieved through the rescheduled augmentations which delayed capital costs expenditures and reduced NPV. The deferment and elimination of the capital costs made up most of the total infrastructure savings; between $76 \%$ and $83 \%$. The capital costs make up a large proportion of the savings as it is the largest cost component in a water supply area (Savic and Walters, 1997; Swamee and Sharma, 2008; Gurung and Sharma, 2014).

While costs reductions were also noted for energy required for pumping energy, this made up only 5\% to 7\% of total infrastructure savings as there were only small reductions $(<8 \%)$ in pumping energy requirements for all water saving scenarios. Since the study area is gravity supplied, the pumping energy requirements are directly related to the volume of water pumped to the storage tanks at a fixed head; that is, less water transported equates to less pumping required. Due to the small differences in pumping volume, low savings in pumping energy costs are realised for the water saving scenarios in this study. Conversely, there may be more apparent differences in energy requirements for a pressure driven water supply system, where the peak water demand influences the energy output of the distribution pumps. Hence, savings in the operation costs may be more noticeable and constitute a higher proportion of network savings. Similarly, the contributory factors may change as a result of differing urban expansion forms within the same area (Farmani and Butler, 2014).

\subsubsection{Customer cost perspective}

The total household water and energy costs savings from installing water saving features ranged between $21 \%$ and $39 \%$ of the baseline NPV, representing considerable savings to the householders. An NPV analysis 
conducted for an individual household on the potential savings and cost for implementing the waters saving features is shown in Table 3. The NCB for installing water efficient appliances and rainwater tanks are immediately apparent to the householders, with the former providing the highest net benefits. Rainwater tanks present positive benefits only if water efficient appliances are installed, since the energy savings from using less hot water are a result of lower water use from using efficient appliances. Such savings highlight the importance of water efficient appliances in contributing to overall savings for the householder.

Table 3 Net cost balance of a single household over a 50-year analysis period

\begin{tabular}{lrrrrr}
\hline Features & Mains water savings & Energy savings & Total savings & Incurred costs & Net cost balance \\
\hline Water efficiency & $\$ 3,432$ & $\$ 4,060$ & $\$ 7,492$ & $\$ 245$ & $\$ 7,247$ \\
Rainwater tanks & $\$ 9,680$ & $\$ 4,060$ & $\$ 13,740$ & $\$ 11,221$ & $\$ 2,518$ \\
Greywater reuse & $\$ 10,522$ & $\$ 4,060$ & $\$ 14,581$ & $\$ 34,108$ & $-\$ 19,527$ \\
\hline
\end{tabular}

\subsection{Incentives and further savings from installing water saving measures}

The water saving measures should be promoted by providing incentives to developers in the form of an alternative water infrastructure charge policy (Gurung et al., 2015, 2016; Sharma et al., 2012). The resulting infrastructure savings has to be reinvested by the water utility though other proactive forms of saving water. This could include the installation of smart water meters and developing a web-portal tool to monitor and inform customers on their water consumption (e.g. Stewart et al., 2010). In addition, such technology will allow water utilities to implement alternative pricing mechanisms, such as time-of-use or seasonal tariffs (Cole and Stewart, 2013; Parker and Wilby, 2013), enabling them to further take advantage of the added network financial benefits.

The reduced energy demand, from lower hot water demand, may potentially provide some benefits to energy providers in the form of potential deferral of infrastructure augmentations. This would reduce capital costs; similar to distributed generation and energy storage (Gil and Joos, 2006). The energy provider, which has its own infrastructure charges, could provide additional financial incentives in alliance with the water utility, to promote the use of alternative water supplies.

The results of the study clearly show the financial benefits for both water suppliers and consumers from using diversified water supply schemes. Additional savings could be achieved through the use of the highest rated available water appliances. The study was constrained to water efficiency appliances higher than the minimum QDC MP 4.1 specifications, meaning that the use of the highest WELS rated efficiency appliances in the market would ensure maximum savings for the householders. The additional costs of the higher rated appliances would be minimal, but would assist in delivering more cost savings to the householder. Moreover, further reductions in the peak demand would be beneficial to the water utility as it directly reduce capital and water infrastructure costs. Hence, a water efficiency strategy aimed at ensuring a high uptake of the maximum rated water efficient appliances should be implemented on a citywide scale.

The importance and true value of alternative water supplies would only be truly appreciated when they provide the necessary back up supply to the traditional mains supply in times of long term droughts, such as 
the one experienced in Australia between 1997 and 2009. During such water shortage periods, the implementation of a scarcity pricing factor, for example a temporary drought pricing (Sahin et al., 2014), would stress the importance of water during times of acute shortages.

\section{Conclusion}

The research investigated the net benefits of installing water saving measures in infill sites in a study area over a 50-year planning horizon. The study indicated, through the modelling exercises, that benefits are present for both water consumers and water utility, and potentially for energy providers as well. From the utility perspective, network cost benefits through the installation of contemporary water supplies can be realised. Hence, water utilities should continually promote their use to achieve long-term benefits of an efficient water supply network. Most of the utility savings arose from the deferral of infrastructure upgrades, with maintenance and pumping energy cost contributing a smaller percentage ( $16 \%$ to $24 \%$ of total infrastructure savings). Further savings in pumping energy cost would be experienced for a pressure driven water supply system, as a result of the much reduced peak demands of alternative water supplies. The installation of the water saving features demonstrated that householders would generally enjoy reduced water and energy bills (21\% to $39 \%$ savings). The water efficient and rainwater scenarios resulted in positive net benefits, whereas the high capital costs of the greywater scenario resulted in a negative net cost balance.

The study fulfilled the objective of obtaining the net benefits for installing water saving measures in a large scale. While considerable cost savings were noted for both the water efficiency and rainwater reuse scenario, further savings could be realised from carrying out additional analysis, such as an economies of scale assessment of large scale developments; potentially making the greywater scenario a more attractive proposition.

\section{Acknowledgements}

The authors are grateful to the City of Gold Coast for their financial and in-kind support.

\section{References}

ABS (Australia Bureau of Statistics) (2015a). 6401.0 - Consumer Price Index, Australia, Sep 2015, Available at: http://www.abs.gov.au/ausstats/abs@.nsf/mf/6401.0 (accessed December 2015)

ABS (Australian Bureau of Statistics) (2015b). 6427.0 - Producer Price Indexes, Australia, Sep 2015, Available at: http://www.abs.gov.au/ausstats/abs@.nsf/mf/6427.0 (accessed December 2015).

AEMC (Australian Energy Market Commission) (2014). Residential Electricity Price Trends, Report 5, December 2014, Sydney

Beal CD, Stewart RA (2011) South East Queensland residential end-use study: Final report. Urban Water Security Research Alliance Technical Report No. 47, Queensland Government, Australia. 
Beal CD, Sharma A, Gardner T, Chong M (2012) A desktop analysis of potable water savings from internally plumbed rainwater tanks in South-East Queensland, Australia. Water Resources Management 26(6):1577-1590.

Carragher BJ, Stewart RA, Beal CD (2012) Quantifying the influence of residential water appliance efficiency on average day diurnal demand patterns at an end use level: A precursor to optimised water service infrastructure planning. Resources, Conservation and Recycling, 62:81-90.

CoGC (City of Gold Coast) (2015). Water and Sewerage Pricing. Available at: http://www.goldcoast.qld.gov.au/documents/bf/Water_and_sewerage_pricing_2015-16.pdf (Accessed December 2015)

Cole G, Stewart RA (2013) Smart meter enabled disaggregation of urban peak water demand: precursor to effective urban water planning. Urban Water Journal 10(3):174-194.

Coombes PJ (2007) Energy and economic impacts of rainwater tanks on the operation of regional water systems. Australian Journal of Water Resources, 11(2):177-191.

DEWS (Department of Energy and Water supply) (2015). Current electricity prices. Available at: https://www.dews.qld.gov.au/electricity/prices/current (Accessed December 2015)

DHPW (Department of Housing and Public Works) (2013) MP 4.1-Sustainable Buildings. Queensland Government, February 2013. Available at: http://www.hpw.qld.gov.au/SiteCollectionDocuments/QDCMP4.1SustainableBuildingsCurrent.pdf (accessed December 2015).

Diaper C (2004) Innovation in on-site domestic water management systems in Australia: A review of rainwater, greywater, stormwater and wastewater utilisation techniques, CSIRO MIT Technical report 2004-073, April 2004.

Domenech L, Sauri D (2011) A comparative appraisal of the use of rainwater harvesting in single and multifamily buildings of the Metropolitan Area of Barcelona (Spain): social experience, drinking water savings and economic cost. Journal of Cleaner Production. 19(6-7):598-608.

DTF (Department of Treasury and Finance). (2003). Use of discount rates in the partnerships Victoria process. Partnerships Victoria-Technical note-July 2003.

EBMUD (East Bay Municipal Utility District). (2008). Water Smart Guide Book: a Water-use Efficiency Plan Review Guide for New Businesses. Oakland, California.

Farmani R, Butler D (2014) Implication of urban form on water distribution systems performance. Water Resources Management, 28(1):83-97.

Farreny R, Gabarrell X, Rieradevall J (2011) Cost-efficiency of rainwater harvesting strategies in dense Mediterranean neighbourhoods. Resources, Conservation and Recycling. 55:686-694. 
Friedler E, Hadari M (2006) Economic feasibility of on-site greywater reuse in multi-storey buildings. Desalination, 190(1-3):221-234.

GHD (2012) Report for North Warrandyte sewerage backlog alternative options assessment, Yarra Valley Water, March 2012. https://s3-ap-southeast-2.amazonaws.com/ehqproductionaustralia/1d91515e090ac7df9da73b7e72bba79ce617084b/documents/attachments/000/01 0/328/original/Alternative_Options_Report.pdf Accessed Dec 2015

Ghisi E, Ferreira D.F. (2007) Potential for potable water savings by using rainwater and greywater in a multi-storey residential building in southern Brazil. Building and Environment 42(7):2512-2522.

Gil HA, Joos G (2006) On the quantification of the network capacity deferral value of distributed generation. IEEE Transactions on Power Systems 21(4):1592-1599.

Gurung TR, Sharma AK, Umapathi S (2012) Economics of scale analysis of communal rainwater tanks, Urban Water Security Research Alliance Technical Report No. 67. Queensland Government, Australia.

Gurung TR, Sharma A (2014) Communal rainwater tank systems design and economies of scale. Journal of Cleaner Production 67:26-36.

Gurung TR, Stewart RA, Sharma AK, Beal CD (2014) Smart meters for enhanced water supply network modelling and infrastructure planning. Resources, Conservation and Recycling 90:34-50.

Gurung TR, Stewart RA, Beal CD, Sharma AK (2015) Smart meter enabled water end-use demand data: platform for the enhanced infrastructure planning of contemporary urban water supply networks. Journal of Cleaner Production, 87:642-654.

Gurung TR, Stewart RA, Sharma AK, Beal CD (2016) Smart meter enabled informatics for economically efficient diversified water supply infrastructure planning. Journal of Cleaner Production, [submitted 21st June 2015, resubmitted following minor comments].

Kenway SJ, Priestley A, Cook C, Seo S, Inman M, Gregory A, Hall M (2008) Energy use in the provision and consumption of urban water in Australia and New Zealand. CSIRO: Water for a Healthy Country National Research Flagship.

Lucas SA, Coombes PJ, Sharma AK (2010) The impact of diurnal water use patterns, demand management and rainwater tanks on water supply network design. Water Science \& Technology: Water SupplyWSTWS 10(1):69-80.

Malinowski P, Stillwell A, Wu, J, Schwarz P (2015) Energy-water nexus: Potential energy savings and implications for sustainable integrated water management in urban areas from rainwater harvesting and gray-water reuse. Journal of Water Resources Planning and Management, doi: 10.1061/(ASCE)WR.1943-5452.0000528, A4015003. 
Mitchell G, Diaper C (2005) UVQ: A tool for assessing the water and contaminant balance impacts of urban development scenarios. Water Science \& Technology 52(12):91-98

Parker JM, Wilby RL (2013) Quantifying Household Water Demand: A Review of Theory and Practice in the UK. Water Resources Management 27(4):981-1011

QCA (Queensland Competition Authority) (2015). SEQ Bulk Water Price Path 2015-18, Final Report, March 2015. http://www.qca.org.au/getattachment/0cddd37b-2d7b-499c-81c4bd477c3db2dc/Seqwater-s-BulkWater-Prices-2015-18.aspx Accessed Dec 2015

Sahin O, Stewart RA, Porter G (2015) Water security through scarcity pricing and reverse osmosis: a system dynamics approach. Journal of Cleaner Production 88:160-171.

Savic DA, Walters GA (1997). Genetic algorithms for least-cost design of water distribution networks. Journal of Water Resources Planning and Management 123:67-77.

SEQ Code (South East Queensland Code) (2013) South East Queensland water supply and sewerage design and construction code. Queensland. http://www.seqcode.com.au/storage/2013-07-01\%20\%20SEQ\%20WSS\%20DC\%20Code\%20Design\%20Criteria.pdf (accessed December 2014).

Sharma AK, Cook S, Tjandraatmadja G, Gregory A (2012) Impediments and constraints in the uptake of water sensitive urban design measures in greenfield and infill developments. Water Science and Technology 65(2):340-352.

Stewart RA, Willis RM, Giurco D, Panuwatwanich K, Capati B. (2010). Web-based knowledge management system: linking smart metering to the future of urban water planning. Australian Planner 47(2):6674.

Stewart RA (2011) Verifying potable water savings by end use for contemporary residential water supply schemes. Waterliness Report Series No. 61, National Water Commission, October 2011.

Swamee PK, Sharma AK (2008) Design of water supply pipe networks, John Wiley and Sons, New Jersey, USA.

Tam VWY, Tam L, Zeng SX (2010) Cost effectiveness and tradeoff on the use of rainwater tank: An empirical study in Australian residential decision-making. Resources, Conservation and Recycling 54:178-186.

Umapathi, S, Chong MN, Sharma AK (2013) Evaluation of plumbed rainwater tanks in households for sustainable water resource management: a real-time monitoring study. Journal of Cleaner Production 42:204-214.

Vieira AS, Beal CD, Stewart RA (2014) Residential water heaters in Brisbane, Australia: Thinking beyond technology selection to enhance energy efficiency and level of service. Energy and Buildings $82: 222-236$. 
Willis RM, Stewart RA, Williams PR, Hacker CH, Emmonds SC, Capati G (2011) Residential potable and recycled water end uses in a dual reticulated supply system. Desalination 272(1-3):201-211.

Zhang Y, Grant A, Sharma A, Chen D, Chen L (2010) Alternative water resources for rural residential development in Western Australia. Water Resources Management 24:25-36. 